\title{
Note \\ Analysis of Glucosamine in Cream Dosage Form and Diffusion Liquid by High Performance Liquid Chromatography
}

\author{
*Daryono H. Tjahjono, Slamet I. Surantaatmadja and Sasanti T. Darijanto \\ School of Pharmacy, Bandung Institute of Technology, Jalan Ganesha 10 Bandung 40132, Indonesia
}

(Manuscript submitted March 30, 2007; accepted June 13, 2007)

\begin{abstract}
A simple and sensitive high performance liquid chromatography (HPLC) method based on a reaction of 1-naphthyl isothiocyanate (NITC) with glucosamine was developed and validated to determine glucosamine in cream dosage form and diffusion liquid. The derivatisation products were cleaned up using styrene divinylbenzene quaternary ammonium ion exchanger and was then analyzed on a reverse-phase $C_{18}$ column $(150 \mathrm{~mm} \times 4.6 \mathrm{~mm}, 5 \mu \mathrm{m})$ using acetonitrile-water-triethylamine (15:85:0.05) as the mobile phase and was detected at wavelength of $254 \mathrm{~nm}$. The detector response was linear in the concentration range of 1-1200 $\mu \mathrm{g} / \mathrm{ml}$. The recovery of glucosamine from cream and diffusion liquid were $95.9-97.4 \%$ and 97.6-98.4\%, respectively. The intra- and inter-day relative standard deviation (\%RSD) was less than $5 \%$.

Key words: glucosamine, anion exchanger, cream, diffusion liquid, HPLC
\end{abstract}

The amino monosaccharide glucosamine (2-amino-2-deoxy-D-glucose) is a natural component of the glycoproteins present in connective tissue and gastrointestinal mucosal membrane and acts as building block of glycosaminoglycans [1-3]. Hypothetical mechanisms by which glucosamine exerts its effects relates to glucosamine-induced reversal of the pro-inflammatory and joint-degenerating effects of interleukin-1, via an inhibitory effect on the interleukin-1 intracellular signaling cascade and especially by the reduction in the activation and nuclear translocation of the transcription factor NF-kB. Other putative mechanisms involve glucosamine as an inhibitor of catabolic enzymes, including matrix metalloproteinases [4].

Typically a salt of glucosamine, either the hydrochloride or sulfate, alone or in combination with other ingradients (for example chondroitin sulfate) are formulated into capsules, tablets and liquids for oral administration and have been marketed heavily over the last two decades. Recently, topical preparations of glucosamine, such as creams, gels and patches have also been developed intensely by pharmaceutical industries. This is due to the transdermal delivery route posses several advantages in therapy compared with oral route, such as circumventing first-pass metabolism or other possible problems associated with passage through gastrointestinal tract, producing relatively constant plasma levels of drugs and improving the patient compliance [5].

Glucosamine does not contain a chromophore absorbing in region useful for UV-vis detection. Therefore, in order to improve the detectability of glucosamine by UV-vis spectroscopy and obtain adequate retention on hydrophobic stationary phase, HPLC methods with pre-analytical derivatisation procedure involving the reaction of amino group of glucosamine with hydrophobic chromophore should be achieved. In the present research we developed a HPLC method to analyzed glucosamine in cream dosage form and its diffusion liquid. Glucosamine was derivatized using 1-naphthyl isothiocyanate (NITC) forming a derivative, which was analyzed by HPLC using UV detection. The developed method was then validated according ICH guidelines [6]. Reaction of glucosamine with NITC using a standard aqueous solution produced a naphthylthiocarbomyl-glucosamine adduct that exhibited favorable UV absorbing properties. NITC derivatization reaction was not very sensitive to water. However, several approaches were undertaken to minimize its presence.

Ion exchange cartridges were introduced into the analytical method in order to take advantage of anionic character of derivatized amine containing component of cream base as well as carboxylic acid groups. A neat chromatogram was obtained upon application of styrene divinylbenzene quaternary ammonium ion exchange in matrices clean up. Derivatized glucosamine was separated on a reverse-phase $C_{18}$ column $(150 \mathrm{~mm} \times 4.6 \mathrm{~mm}, 5$ $\mu \mathrm{m})$ using acetonitrile-water-triethylamine (15:85:0.05) as the mobile phase and was detected at wavelength of $254 \mathrm{~nm}$. The representative chromatograms of the extracted blank cream, cream dosage form and a diffusion liquid of glucosamine showed that the analyte was well separated using the present chromatographic conditions. Naphthylthiocarbomyl-glucosamine adduct was eluted at $7.28 \mathrm{~min}$. No interfering peaks from the other 
components were observed at the retention time of glucosamine derivative.

Calibration curves of glucosamine were found to be linear over the range of $1-1200 \mu \mathrm{g} / \mathrm{ml}$ with the lower limit of quantitation (LOQ) of $2.5 \mu \mathrm{g} / \mathrm{g}$ and the limit of detection (LOD) of $0.5 \mu \mathrm{g} / \mathrm{g}$ at a signal-to-noise ratio of 3 . The correlation coefficient was found to be better than 0.99. A typical regression equation was $y=10280 x+$ $60313(r=0.9998, n=5)$.

The intra-day RSDs were 3.11, 3.15 and $1.75 \%$, and the inter-day RSDs were $4.06,4.68$ and $1.72 \%$ for spiked cream at concentrations of 5, 20 and $100 \mathrm{mg} / \mathrm{g}$, respectively, with the accuracy ranged $96.60-103.54 \%$. For diffusion liquid the intra-day RSDs were 2.50, 0.33 and 4.84\%, and the inter-day RSDs were $2.74,1.85$ and $4.90 \%$ for spiked diffusion liquid at concentrations of 80,200 and $1200 \mu \mathrm{g} / \mathrm{ml}$, respectively. The accuracy of determination of glucosamine in diffusion liquid was in the range of $95.50-109.43 \%$ (Table 1). The mean of extraction recovery for glucosamine in cream ranged between 95.9 and $97.4 \%$, while recovery of glucosamine in diffusion liquid was more than $97.6 \%$.

Table 1 Accuracy and precision of glucosamine in cream and diffusion liquid

\begin{tabular}{|c|c|c|c|c|c|c|c|}
\hline $\begin{array}{l}\text { Prepared } \\
\text { concentration }\end{array}$ & $\begin{array}{l}\text { Mean of found } \\
\text { concentration }\end{array}$ & $\begin{array}{c}\text { Accuracy } \\
(\%)\end{array}$ & $\begin{array}{l}\text { RSD } \\
(\%)\end{array}$ & $\begin{array}{l}\text { Mean of found } \\
\text { concentration }\end{array}$ & $\begin{array}{c}\text { Accuracy } \\
(\%)\end{array}$ & $\begin{array}{l}\text { RSD } \\
(\%)\end{array}$ & $n$ \\
\hline Intra-day & & & & Inter-day & & & \\
\hline \multicolumn{8}{|l|}{ Cream $(\mathrm{mg} / \mathrm{g})$} \\
\hline 5 & 4.83 & 96.60 & 3.11 & 4.88 & 97.60 & 4.06 & 5 \\
\hline 20 & 19.75 & 98.75 & 3.15 & 19.68 & 98.40 & 4.68 & 5 \\
\hline 100 & 102.52 & 102.52 & 1.75 & 103.54 & 103.54 & 1.72 & 5 \\
\hline \multicolumn{8}{|c|}{$\begin{array}{l}\text { Diffusion liquid } \\
(\mu \mathrm{g} / \mathrm{ml})\end{array}$} \\
\hline 80 & 76.75 & 95.93 & 2.50 & 76.4 & 95.50 & 2.74 & 5 \\
\hline 400 & 437.7 & 109.43 & 0.33 & 434.2 & 108.55 & 1.85 & 5 \\
\hline 1200 & 1199.4 & 99.95 & 4.84 & 1195 & 99.58 & 4.90 & 5 \\
\hline
\end{tabular}

In long-term stability test, the results demonstrated that there were no significant differences $(\leq \pm 5 \%)$ among the observed concentrations at zero, 10, 20,30 and 40 days stored at room temperature, indicating glucosamine was stable in cream dosage form for at least 40 days when stored at room temperature. In short-term stability test after derivatization, the results showed that no significant differences $(\leq \pm 5 \%)$ was found among the peak areas at zero time and after $4,8,12$ and $24 \mathrm{~h}$ at $4{ }^{\circ} \mathrm{C}$ after derivatisation, which indicated the stability of NITC derivative of glucosamine in cream dosage form at $4{ }^{\circ} \mathrm{C}$.

Application of the validated method in determination of glucosamine in commercial cream dosage form (Mediflex ${ }^{\circledR}$ ) and our developed cream formulas showed that the average recovery was within $100.0 \pm 5.0 \%$ of label claim, and RSD of $1.6 \%$, indicating excellent precision. The developed method was also applied for in vitro diffusion study [7] of glucosamine from cream dosage form. The results showed a good precision with RSD less than $5 \%$. Study on determination of glucosamine flux through membrane as well as apparent permeability coefficient are currently underway and will be reported elsewhere.

\section{Acknowledgements}

This research was supported in part by PT Kalbe Farma, Bekasi, Indonesia. The authors thank Mrs. Lusiana, Miss Nur Hayati and Mrs. Enok Herlina for their excellent assistance.

\section{References}

1) D.T. Felson, Y. Zhang, Arthritis Rheum., 41, 1343-1355 (1998).

2) D. Uebelhart, E.J. Thonar, J. Zhang, J.M. Williams, Osteoarthritis Cartilage, 6 (Suppl. A), 6-13 (1998).

3) C. Bassleer, L. Rovati, P. Franchimont, Osteoarthritis Cartilage, 6 (Suppl. A), 427-434 (1998).

4) A. Das, T.A. Hammad, Osteoarthritis Cartilage, 8, 343-350 (2000).

5) B.W. Barry, "Dermatological Formulations: Percutaneous Absorption", Mercel Dekker, New York, 1983.

6) International Conference of Harmonization (ICH) Reviewer Guidance: Validation of Chromatographic Methods, Center for Drug Evaluation and Research (CDER), November 1994, http://www.fda.gov/cder/guidance/ cmc3.pdf

7) U. Mar'u, P. Michaud, J. Garrique, J. Oustrin, R. Rouffiac, J. Pharm. Belg., 37, 207-213 (1982). 